\title{
Prevalence of White Spot Lesion in Nepalese Patients with Fixed Orthodontic Appliance
}

\author{
Dr Sandhya Shrestha,' Dr Rabindra Man Shrestha² \\ 'Lecturer, Dept of Conservative Dentistry \& Endodontics, \\ ${ }^{2}$ Associate Professor, Dept of Orthodontics \\ Kantipur Dental College, Kathmandu, Nepal
}

Correspondence: rabindraortho@gmail.com

\section{ABSTRACT}

Introduction: Enamel decalcification in the form of white spot lesion is a common complication seen in patients with fixed orthodontic appliances.

Objective: To determine the prevalence of white spot lesion among Nepalese fixed orthodontic patients, to compare the occurrence of WSL among the patients with lesser and greater duration of treatment, and to compare between the gender groups.

Materials \& Method: A cross-sectional study was done to compare the prevalence of WSL between 300 orthodontic patients and 100 non-orthodontic subjects. Further comparison was done between the mean treatment duration between orthodontic subjects of 6-18 months and >18 months, and between male and female samples. Subjects were visually examined on second premolar to second premolar in both maxillary and mandibular arches using Gorelick's WSL index. Descriptive statistics were calculated and independent t-test was used to compare the difference between the groups. The p-value $<0.05$ was considered significant.

Result: The prevalence of WSL in Nepalese orthodontic patients was 54.3\%; among them prevalence was $40 \%$ in lesser treatment duration group and $68.7 \%$ in greater treatment duration group. The study found significant difference between untreated nonorthodontic group and orthodontically treated group with respect to the number of teeth affected with WSL. Also, there was significant difference between the categories of orthodontic treatment duration. There was no significant difference between male and female samples.

Conclusion: Fixed orthodontic treatment increase the risk of white spot lesion. Duration of orthodontic treatment also showed significant increase in the occurrence of WSL.

Key words: fixed orthodontic appliance, oral hygiene, plaque, white spot lesion

\section{INTRODUCTION}

Enamel decalcification in the form of white spot lesion (WSL) is a common side effect seen in patients with fixed orthodontic appliances. Review of literature on prevalence of WSL associated with orthodontic treatment showed various reports ranging from $2 \%$ to $97 \%$. $^{1,2,3}$ The occurrence of white spot lesion is related to increased susceptibility of plaque accumulation and retention on tooth surface around the orthodontic brackets and auxiliaries of the fixed orthodontic appliance system. The cleansing of such areas requires extra time and effort by the patient using additional cleansing aids, frequent motivation and reinforcement by the orthodontist.

The white spot lesion has been defined as the subsurface enamel porosity from carious demineralization that presents itself as a milky white opacity when located on smooth surfaces ${ }^{4}$ This surface retains its ability to be remineralized with the shift in environment to increase in fluoride availability and decrease in plaque accumulation. When there is unfavorable condition of increased duration of plaque retention, such white lesions cause break in the enamel surface continuity leading to cavitation. ${ }^{5,6}$
The present study aims to determine the prevalence of white spot lesion among Nepalese fixed orthodontic patients and compare with the untreated normal subjects. The study also attempts to compare the occurrence of WSL among the patients with lesser and higher duration of fixed orthodontic treatment and compare the occurrence of WSL between gender groups.

\section{MATERIALS AND METHOD}

A cross sectional study was conducted to determine the prevalence of white spot lesion among orthodontic patients and non-orthodontic subjects. The purposive sampling was done to compare the prevalence of WSL of 300 orthodontic patients (study group) with 100 untreated subjects (control group). The study group was further divided in to two categories based on the treatment duration of 6-18 months and more than 18 months to assess the occurrence of WSL between two categories. All subjects were within the age range of 13-30 years representing both genders. The study group comprised of orthodontic patients with fixed appliance of 0.018 " Roth brackets in both arches. The subjects comprised of all types of malocclusions with more than 6 months of treatment 
duration. The control group comprised of similar age cohorts with normal occlusion or varying degree of malocclusion without the previous history of orthodontic treatment.

The study was performed after receiving the permission from Institutional Review Committee. A performa was developed comprising of index number, subject's name, age, sex, duration of orthodontic treatment and WSL assessment table for data collection. The teeth considered for examination were second premolar to second premolar in both maxillary and mandibular arches. Molars were excluded from the study as many molar teeth were banded obviating the visibility for WSL. The missing teeth were not considered in the study. The verbal consent was taken from the subjects before examination. The teeth were visually examined on the buccal surface after removing plaque with the help of instruments and air water spray drying. Gorelick's WSL index' was used to determine the white spot lesion.

\section{Gorelick WSL Index}

- Score 1 no white spot formation

- Score 2 slight white spot formation

- Score 3 excessive white spot formation

- Score 4 white spot formation with cavitation

Examination was done in the dental chair with good illumination at four various orthodontic practices of a single orthodontist. The study was conducted at Kantipur Dental College \& Hospital, Samaj Dental Hospital, Dental Arch Clinic and Dental Square Clinic, Kathmandu during July to September, 2013.
Data analysis was done using SPSS version 16.0 software program. Descriptive statistics were calculated and independent Student's t-test was used to compare the difference between the groups. The $p<0.05$ was considered significant and confidence level was predetermined at $95 \%$.

\section{RESULT}

The samples comprised of 300 orthodontic patients and 100 untreated subjects. The orthodontic subjects with treatment duration 6-18 months were 150 and more than 18 months were 150 in number. The mean age of the orthodontic subjects was 19.19 years (SD 4.515) and the mean is of non-orthodontic subjects was 19.63 years (SD 4.069). The female subjects were 185 and male were 115 among the orthodontic subjects.

Descriptive statistics of mean, standard deviation and range of the number of teeth affected with white spot lesion among non-orthodontic and orthodontic groups is given in Table 1. The frequency distribution of white spot lesion in all teeth examined among all orthodontic patients is given in Figure 1.

Figure 1 illustrates the frequency distribution of white spot lesion in individual tooth among all orthodontic patients. The prevalence of WSL in Nepalese orthodontic patients was $54.3 \%$; among them prevalence was $40 \%$ in 6-18 months treatment duration group and $68.7 \%$ in more than 18 months treatment duration group (Table 2). Table 2 also depicts the number of cases affected with WSL with respect to extent of teeth.

Table 1: Descriptive statistics of number of teeth involved with WSL

\begin{tabular}{|l|c|c|c|c|}
\hline \multicolumn{1}{|c|}{ Group } & Number $(\mathbf{n})$ & Mean & SD & Range \\
\hline Untreated non-orthodontic & 100 & 0.65 & 1.925 & $0-13$ \\
\hline 6-18 months orthodontic & 150 & 1.04 & 1.621 & $0-9$ \\
\hline$>18$ months orthodontic & 150 & 2.71 & 3.180 & $0-20$ \\
\hline Total orthodontic & 300 & 2.40 & 3.080 & $0-20$ \\
\hline
\end{tabular}

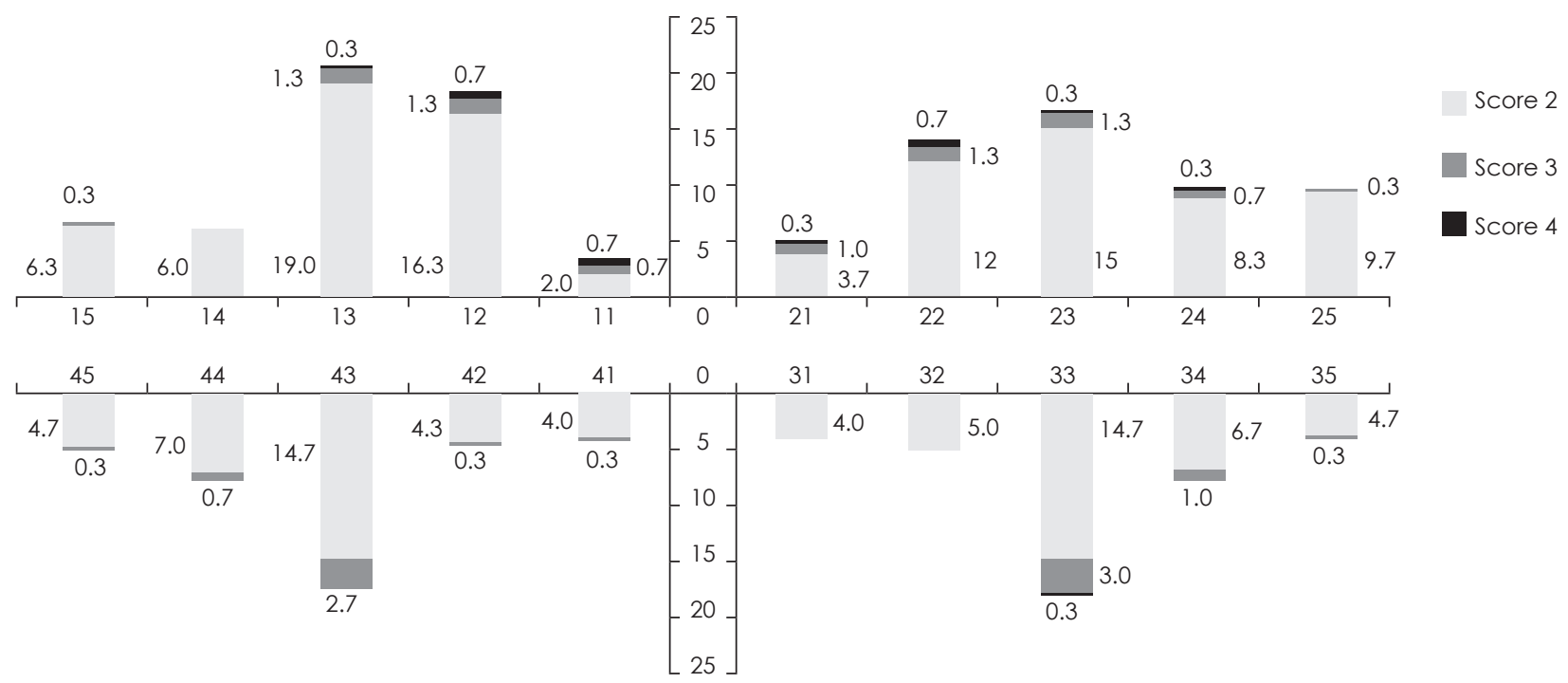

Figure 1: Frequency distribution of WSL in all teeth examined among all orthodontic patients 
The study found statistically significant difference between untreated group and orthodontically treated group with respect to the number of teeth affected with WSL (Table 3). Similarly, there was a significant difference between the categories of orthodontic patients of 6-18 months and more than 18 months duration (Table 4). However, there was no significant difference between male and female orthodontic patients with respect to the occurrence of WSL (Table 5).

Table 2: Occurrence and extent of WSL

\begin{tabular}{|l|c|c|c|c|c|c|}
\hline \multicolumn{1}{|c|}{ Group } & \multirow{2}{*}{$\mathbf{n}$} & \multicolumn{2}{|c|}{ Occurrence of WSL } & \multicolumn{3}{|c|}{ Extent of WSL } \\
\cline { 2 - 7 } & & $\mathbf{n}$ & $\mathbf{\%}$ & $\mathbf{1}$ tooth & $\mathbf{2 - 4}$ teeth & $\mathbf{> 4}$ teeth \\
\hline Untreated non-orthodontic & 100 & 20 & 20 & $7(35 \%)$ & $8(40 \%)$ & $5(25 \%)$ \\
\hline 6-18 months orthodontic & 150 & 60 & 40 & $15(25 \%)$ & $38(63 \%)$ & $7(11.21 \%)$ \\
\hline$>18$ months orthodontic & 150 & 103 & 68.7 & $16(15.5 \%)$ & $55(53.39 \%)$ & $32(31.06 \%)$ \\
\hline Total orthodontic & 300 & 163 & 54.3 & $31(19.01 \%)$ & $93(57.05 \%)$ & $39(23.92 \%)$ \\
\hline
\end{tabular}

Table 3: t-Test for the difference between untreated subjects and orthodontic patients

\begin{tabular}{|l|c|c|c|c|c|}
\hline \multicolumn{1}{|c|}{ Group } & $\mathbf{n}$ & Mean & SD & SEM & p-Value \\
\hline Untreated non-orthodontic & 100 & 0.65 & 1.925 & 0.192 & \multirow{2}{*}{$0.000^{*}$} \\
\hline Orthodontically treated & 300 & 2.40 & 3.080 & 0.178 & \\
\hline
\end{tabular}

*significant at $p<0.05$

Table 4: t-Test for the difference between orthodontic patients 6-18 months and >18 months

\begin{tabular}{|r|c|c|c|c|c|}
\hline \multicolumn{1}{|c|}{ Group } & $\mathbf{n}$ & Mean & SD & SEM & p-Value \\
\cline { 1 - 5 } 6-18 mths & 150 & 1.04 & 1.621 & 0.132 & $0.000^{*}$ \\
\hline$>18 \mathrm{mths}$ & 150 & 3.75 & 3.563 & 0.291 & \\
\hline
\end{tabular}

*significant at $p<0.05$

Table 5: t-Test for the difference between gender groups among orthodontic patients

\begin{tabular}{|l|c|c|c|c|}
\hline \multicolumn{1}{|c|}{ Group } & $\mathbf{n}$ & Mean & SD & SEM \\
\hline Female & 185 & 2.63 & 3.347 & 0.246 \\
\hline Male & 115 & 2.03 & 2.563 & 0.081 \\
\hline
\end{tabular}

Not significant

\section{DISCUSSION}

The present study reveals white spot lesion as a serious problem among Nepalese orthodontic patients with fixed appliance. In spite of proper oral hygiene instruction, patient awareness and meticulous maintenance practice by the patient, occurrence of WSL may be inevitable in certain cases. The plaque retention areas make the oral hygiene difficult leading to increase in dental caries and present the unaesthetic areas of white spot lesions of various severities on tooth surface after orthodontic treatment. ${ }^{7}$

The study showed $54.3 \%$ occurrence of white spot lesion in Nepalese fixed orthodontic patients. The present finding is similar to the findings of Gorlick, 1 which showed prevalence of $50 \%$ in orthodontically treated patients. Hadler-Olsen ${ }^{8}$ reported prevalence of WSL after orthodontic treatment to be $60 \%$; the data increased up to $97 \%$ in a study of Boersma el al. ${ }^{9}$

The study showed $54.3 \%$ overall prevalence of white spot lesion among Nepalese fixed orthodontic patients; among which $40 \%$ were in 6-18 month treatment group and $68.7 \%$ in more than 18 months treatment group. These findings may be attributed to the exposure duration of the teeth towards white spot lesion formation and the type of appliance used in the later stage of the orthodontic treatment that incorporates loops, hooks, and elastics that make the cleaning more difficult to the patient. Forsberg et $\mathrm{a}^{10}{ }^{10}$ and Sukontapatipark et $a^{\prime \prime}$ observed increased microbial colonies of Streptococcus mutans and Lactobacillus associated with elastomeric ligature rings. According to Øgaard et al, ${ }^{12}$ WSL becomes noticeable around the brackets within one month after bonding but the cavitation of the lesion requires at least 6 months duration. Fortunately cavitation is seldom seen in orthodontic subjects, which may be because of the oral hygiene measures practiced when initial white spot lesions are noticed. The present study considered orthodontic patients with more than 6 months duration in view of this potential duration for developing WSL.

It has been noticed that majority of WSL were present in cervical areas of the brackets. Many patients had hyperplastic gingiva especially in upper premolar region as the bracket placement were near to the gingival margin and placement of ligatures, coil springs, elostomeric chains are needed on premolars and canines during canine retraction phase. 
These auxiliaries make the brushing inefficient resulting in inflammatory gingival enlargement. To enhance the visibility of WSL beneath enlarged gingiva, air blowing and reflection of the gingiva were done wherever needed during examination. Since the molars were not taken into consideration in this study due to the varied use of molar bands or bondable molar tubes, the prevalence of WSL might be still high as the molars are also found to be most affected teeth with WSL as reported by $\varnothing$ gaard $^{13}$ and Mizrahi. ${ }^{14}$

The present study found no difference in the occurrence of WSL between male and female subjects, similar findings was described by Gorlick; contrarily, Boersma ${ }^{9}$ and Tufekci'15 found WSL increased is males.

Geiger et $a^{16}$ found maxillary lateral incisor and canine as the most frequently affected teeth by WSL, present study also revealed the similar result. Regarding the extent of WSL i.e. number of teeth affected; the present study showed the higher proportion of cases affected with lesser teeth involvement in untreated cases, while more number of teeth were found to be involved in orthodontically treated cases with greater duration (Table 2).

\section{CONCLUSION}

The present study agrees with various other studies that the fixed orthodontic treatment increase the risk of white spot lesion in mild to moderate form, seldom leads to cavitations. The occurrence of WSL is significantly higher in fixed orthodontic patients as compared to non-treated subjects.
Duration of orthodontic treatment also showed significant increase in the prevalence of WSL.

\section{RECOMMENDATION}

The authors would like to suggest practicing orthodontists to minimize the white spot lesion by incorporating following changes in their practice:

- Instruction and reinforcement of proper oral hygiene maintenance

- Regular use of cleansing aids like orthodontic brush, interdental brush

- Dietary counseling to avoid sweet foodstuffs and aerated drinks

- Regular use of fluoride toothpaste, fluoride mouthrinse

- Periodic use of fluoride varnish, chlorhexidine gel around the brackets

- Use of tooth mousse or special fluoride pastes if rapid progression of WSL seen

- Removal of extra adhesives around the brackets

- Periodic oral prophylaxis

- Incorporation of simpler techniques with lesser use of accessories in appliances

- Use of fluoride releasing elastomeric ligatures

- Use of Glass ionomer-based adhesive for bands and brackets

- Timely management of inflamed and hyperplastic gingiva.

\section{OJN}

\section{REFERENCES}

1. Gorelick L, Geiger AM, Gwinnett AJ. Incidence of white spot formation after bonding and banding. Am J Orthod Dentofac Orthop. 1982: 81:93-98.

2. Øgaard B, Larsson E, Henriksson T, Birkhed D, Bishara SE. Effects of combined application of antimicrobial and fluoride varnishes in orthodontic patients. Am J Orthod Dentof Orthop. 2001; 120: 28-35.

3. Mitchell L. Decalcification during orthodontic treatment with fixed appliances- An overview. Br J Orthod. 1992; 19:199-205.

4. Summitt JB, Robbins JW, Schwartz RS. Fundamentals of Operative Dentistry: A Contemporary Approach. 2006; 3rd Ed., Hanover Park, IL, Quintessence Pub, p.2-4.

5. Backer Dirks O. Posteruptive changes in dental enamel. J Dent Res. 1966; 45:503-11.

6. Vonder Fehr FR, Loe H, Theilade E. Experimental caries in man. Caries Res. 1970; 4:131-48.

7. Shrestha S, Shrestha L, Shrestha N, Shrestha RM. Effect of orthodontic treatment on occurrence of dental caries. Orthod J Nep. 2013; 3:1:31-36.

8. Hadler-Olsen S, Sandvik K, El-Agroudi MA, Øgaard B. Incidence of caries and white spot lesions in orthodontically treated adolescents with a comprehensive caries prophylactic regimen - A prespective study. Euro J Orthod. 2011; 12:1-7.

9. Boersma JG, van der Veen MH, Lagerweij MD, Bokhout B. Caries prevalence measured with QLF after treatment with fixed orthodontic appliances: Influencing factors. Caries Res. 2005; 39:41-47.

10. Forsberg CM, Brattstrom V, Malamberg E, Nord CE. Ligature wires and elastomeric rings: Two methods of ligation, and their association with microbial colonization of streptococcus mutans and lactobacilli. Eur J Orthod. 1991; 13: 416-20.

11. Sukontapatipark W, El-Agroudi MA, Selliseth NJ, Thunold K, Selvig KA. Bacterial colonization associated with fixed orthodontic appliances. A scanning electron microscopic study. Euro J Orthod. 2001; 23:475-484.

12. Øgaard B, Rolla G, Arends J. Orthodontic appliances and enamel demineralization. Part 1. Lesion development. Am J Orthod Dentofac Orthop. 1988; 94:68-73.

13. Øgaard B. Prevalence of white spot lesions in 19-year-olds: A study on untreated and orthodontically treated persons 5 years after treatment. Am J Orthod Dentofac Orthop. 1989; 96:423-27.

14. Mizrahi E. Surface distribution of enamel opacities following orthodontic treatment. Am J Orthod. 1983; 84: 323-31.

15. Tufekci E, Dixon JS, Gunsolley JC, Lindaver SJ. Prevalence of white spot lesions during orthodontic treatment with fixed appliances. Angle Orthod. $2011 ; 81: 2: 206-10$.

16. Geiger AM, Gorelick L, Gwinnett AJ, Griswold PG. The effect of a fluoride program on white spot formation during orthodontic treatment. Am J Orthod Dentofac Orthop. 1988; 94:123-128. 